\title{
ARTICLE
}

\section{A metal-ion-responsive adhesive material via switching of molecular recognition properties}

Takashi Nakamura', Yoshinori Takashima¹, Akihito Hashidzume ${ }^{1}$, Hiroyasu Yamaguchi ${ }^{1}$ \& Akira Harada ${ }^{1,2}$

Common adhesives stick to a wide range of materials immediately after they are applied to the surfaces. To prevent indiscriminate sticking, smart adhesive materials that adhere to a specific target surface only under particular conditions are desired. Here we report a polymer hydrogel modified with both $\beta$-cyclodextrin $(\beta C D)$ and 2,2'-bipyridyl (bpy) moieties ( $\beta C D$-bpy gel) as a functional adhesive material responding to metal ions as chemical stimuli. The adhesive property of $\beta C D$-bpy gel based on interfacial molecular recognition is expressed by complexation of metal ions to bpy that controlled dissociation of supramolecular crosslinking of $\beta C D$-bpy. Moreover, adhesion of $\beta C D$-bpy gel exhibits selectivity on the kinds of metal ions, depending on the efficiency of metal-bpy complexes in cross-linking. Transduction of two independent chemical signals (metal ions and host-guest interactions) is achieved in this adhesion system, which leads to the development of highly orthogonal macroscopic joining of multiple objects.

\footnotetext{
${ }^{1}$ Department of Macromolecular Science, Graduate School of Science, Osaka University, 1-1 Machikaneyamacho, Toyonaka, Osaka 560-0043, Japan. ${ }^{2}$ Japan Science and Technology Agency (JST), Core Research for Evolutional Science and Technology (CREST), 7 Gobancho, Chiyoda-ku, Tokyo 102-0076, Japan. Correspondence and requests for materials should be addressed to A.H. (email: harada@chem.sci.osaka-u.ac.jp).
} 
A dhesion of two different materials plays a vital part in a vast field of industries and everyday life ${ }^{1,2}$. Reflecting its importance, many theories have been proposed to analyse and explain the mechanism of adhesion, such as mechanical theory, electronic theory, adsorption theory, diffusion theory and chemical bonding theory ${ }^{3}$. Although many attempts have been made to generalize the adhesion process, a consistent explanation is still difficult due to the many factors involved. From a microscopic point of view, some theories attribute the adhesion force to the interatomic forces such as van der Waals interactions and electrostatic interactions. However, discussion based on molecular scales beyond the level of individual functional groups has been hardly brought up. In terms of application, demand is high for smart adhesives that exert their adhesion abilities to a specific surface at a desired timing ${ }^{4-6}$. Adhesives responsive to external stimuli such as $\mathrm{pH}^{7}$, light ${ }^{8}$, temperature ${ }^{9}$, humidity ${ }^{10}$ and magnetic force ${ }^{11}$ have been studied and developed, whose switching abilities were achieved mainly by altering the physical nature and morphology of the polymers. To realize precise and orthogonal surface selectivity in adhesion ${ }^{12}$, one promising approach is to utilize chemical interactions at the surface of the adherent. However, partly due to the difficulty in understanding adhesion process, the creation of such intelligent materials with chemical selectivity is still a big challenge.

Recently, we have found adhesion phenomena between soft materials through molecular recognition ${ }^{13-17}$. In this case, a polymer hydrogel modified with cyclodextrins as host moieties showed chemically selective adhesion ability to a specific counterpart that possessed complementary hydrophobic guest moieties through host-guest interaction. Furthermore, conversion of the guest moieties in the adhesive targets by external stimuli such as light ${ }^{18}, \mathrm{pH}^{19}$ and solvent ${ }^{20}$ changed their affinities to cyclodextrin hosts, and realized ON/OFF adhesion switching between the hydrogels. There is also a report on macroscopic coordination bonding of the hydrogels through axial coordination of L-histidine ligand to an iron-porphyrin ${ }^{21}$. In the study, a hydrogel modified with freebase porphyrin did not interact with a gel possessing L-histidine, but addition of $\mathrm{FeCl}_{3}$ led to the metalation of porphyrins and the acquisition of its adhesion property.

In the pursuit of smart adhesive materials that stick to a desired target in response to specific stimuli, we have conceived to control molecular recognition ability of hosts in adhesive materials by modifying them with suitable inhibitory guests whose inclusion properties can be switchable. In this work, we focus on metal ions in surrounding environment as chemical stimuli. Metal ions are widely utilized as chemical stimuli to control living organisms ${ }^{22}$, supramolecular systems $s^{23-25}$ or properties of soft materials like gels $^{26-32}$, for their chemical selectivity, versatility and reversible nature of coordination bonds. Herein, we report a metal-ionresponsive functional material that can switch their chemically selective adhesion property by regulating inhibitory inclusion of metal ligands to host moieties. $\beta C D$-bpy gel, a polyacrylamide hydrogel modified with both $\beta$-cyclodextrin $(\beta C D)$ moieties and ligands with $2,2^{\prime}$-bipyridyl (bpy) moieties that have a molecular size proper to the cavity of $\beta C D$, is created (Fig. 1a). In the hydrogel, the hydrophobic bpy moiety is included in the cavity of $\beta C D$ to form supramolecular cross-linking ${ }^{33-41}, \beta C D-b p y$, in the polymer gel, which suppresses the molecular recognition abilities of $\beta C D$. On the addition of metal ions, bpy moieties are complexed with them, and thereby charged metal-bpy complexes are released from $\beta C D$ cavities to form 'free' $\beta C D$ units (Fig. 1b). In the absence of metal ions, $\beta C D$-bpy gel (metal-ion-responsive host gel) do not adhere to $t \mathrm{Bu}$ gel (guest gel), a polyacrylamide gel possessing $t \mathrm{Bu}$ groups that can be included in $\beta \mathrm{CD}$. In contrast, in the presence of metal ions reacting with bpy, supramolecular cross-links between $\beta C D$ and bpy in $\beta C D$-bpy gel is dissociated, and adhesion to $t \mathrm{Bu}$ gel is achieved through the formation of host-guest complex $\beta \mathrm{CD}-t \mathrm{Bu}$ on the interface of the two gels (Fig. 1c). Furthermore, the adhesive ability of $\beta C D$-bpy gel varies with the kinds of metal ions, whose chemical selectivity is explained by the gel's property change depending on the resulting metal-bpy complexes.

\section{Results}

Preparation of $\boldsymbol{\beta C D}$-bpy gel. Polyacrylamide was selected as the main chain in this study because interactions of $-\mathrm{CONH}_{2}$ groups with cyclodextrins ${ }^{13}$ or metal ions ${ }^{42}$ are known to be small. $\beta C D$-bpy gel was prepared by radical copolymerization of acrylamide (AAm), mono(6-deoxyacrylamido)- $\beta$-cyclodextrin $(\beta C D A A m)^{13}, \quad 5$-acrylamidomethyl-5'-methyl-2,2'-bipyridine (bpyAAm) and $N, N^{\prime}$-methylenebisacrylamide (MBAAm) in dimethyl sulfoxide (DMSO), followed by the replacement with $\mathrm{H}_{2} \mathrm{O}$ and used as a hydrogel. The feed ratio of the monomers used in the preparation was optimized as follows to realize suitable supramolecular cross-linking and hardness of the gel (Supplementary Table 1): AAm: $92 \mathrm{~mol} \%$, $\beta$ CDAAm: $3 \mathrm{~mol} \%$, bpyAAm: $3 \mathrm{~mol} \%$, MBAAm $2 \mathrm{~mol} \%$. $\beta C D-b p y$ gel was characterized by ${ }^{1} \mathrm{H}$ solid-state field-gradient magic anglespinning (FG-MAS) NMR measurements (Fig. 2a). The signals for both $\beta C D$ and bpy moieties were observed, which confirmed the introduction of both groups into the acrylamide polymer gel scaffold. From integral ratios of the signals, the mol\% contents were determined to be 2.2 and $3.0 \mathrm{~mol} \%$ for $\beta C D$ and bpy moieties, respectively. These values were also supported by elemental analysis (Methods). As reference materials, $\beta C D$ gel, bpy gel and AAm gel were also prepared according to the same procedure with $\beta C D-b p y$ gel (Fig. $2 b$ ).

Supramolecular cross-linking in $\boldsymbol{\beta C D}$-bpy gel. The inclusion properties of $\beta C D$ and bpy were investigated on small molecules in solution. The binding constant $K_{\mathrm{a}}\left[\mathrm{M}^{-1}\right]$ between $2,2^{\prime}$-bipyridyl and $\beta C D$ was determined to be $1.0 \times 10^{2}\left(\mathrm{D}_{2} \mathrm{O}, 298 \mathrm{~K}\right)$ by a ${ }^{1} \mathrm{H}$ NMR titration experiment (Supplementary Figs 1,2$)^{43}$, which showed a modest affinity of 2,2'-bipyridyl to the cavity of $\beta C D$. The inclusion was also confirmed by using their acrylamide derivatives, $\beta C D A A m$ and bpyAAm (Supplementary Fig. 3). Although bpyAAm was almost insoluble in $\mathrm{D}_{2} \mathrm{O}$ at room temperature, addition of 1 eq. of $\beta C D A A m(10 \mathrm{mM})$ dissolved $10 \%$ of bpyAAm through the formation of inclusion complexes $\beta$ CDAAm-bpyAAm. These data show that bpy can be included in the $\beta C D$ 's cavity, and that it acts as an inhibitor to $\beta C D$ as a host.

Supramolecular cross-linking of $\beta C D$-bpy in $\beta C D$-bpy gel was investigated. Figure $2 c$ showed the swelling ratios $Q(=$ (the weight of a swollen gel)/(the weight of the corresponding dried gel) of $\beta C D-b p y$ gel and its reference gels in DMSO and $\mathrm{H}_{2} \mathrm{O}$, respectively. After replacing the solvent from DMSO to $\mathrm{H}_{2} \mathrm{O}$, $\beta C D-b p y$ gel was largely contracted $(Q=25.1$ and $=6.7$ for DMSO and $\mathrm{H}_{2} \mathrm{O}$, respectively) compared with the other gels. This contraction is explained by an increase in crosslink density on the formation of the inclusion complex $\beta C D-b p y$ in the polymer network. To demonstrate supramolecular cross-linking in $\beta C D-$ bpy gel, the size change of the gel on treatment with organic molecules that disrupt the formation of the host-guest complex was investigated (Fig. 2d,e). After immersing in a $10-\mathrm{mM}$ aqueous solution of $\beta C D$ (a competitive host) or 1-admantanecarboxylic acid sodium salt (AdCANa, a competitive guest), $\beta C D$-bpy gel was swollen up to $110 \pm 2$ or $161 \pm 5 \%$ (length ratio), respectively. The expansion of $\beta C D$-bpy gel was larger than that of the other gels, except in the case of bpy gel immersed in $\beta C D$ solution, which can be explained by change in polymer's hydrophilicity 
a
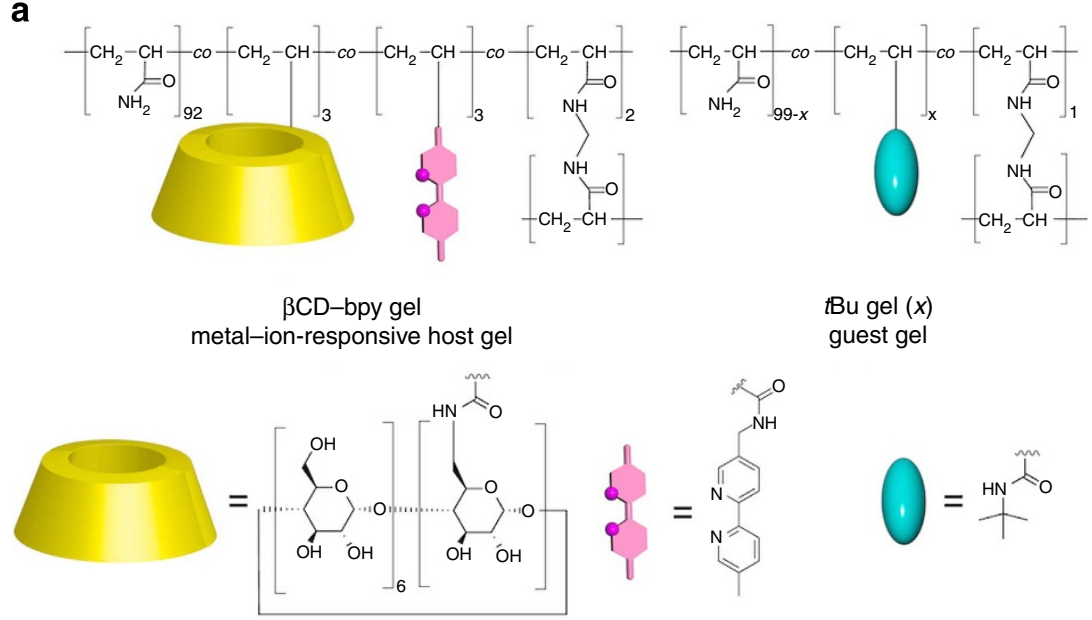

b

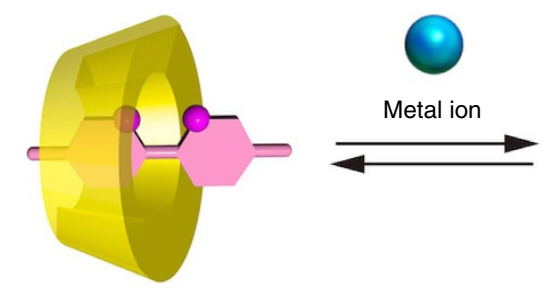

Recognition OFF

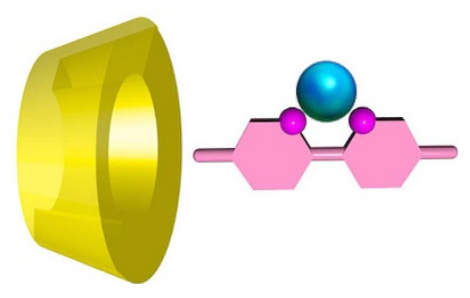

Recognition ON

C

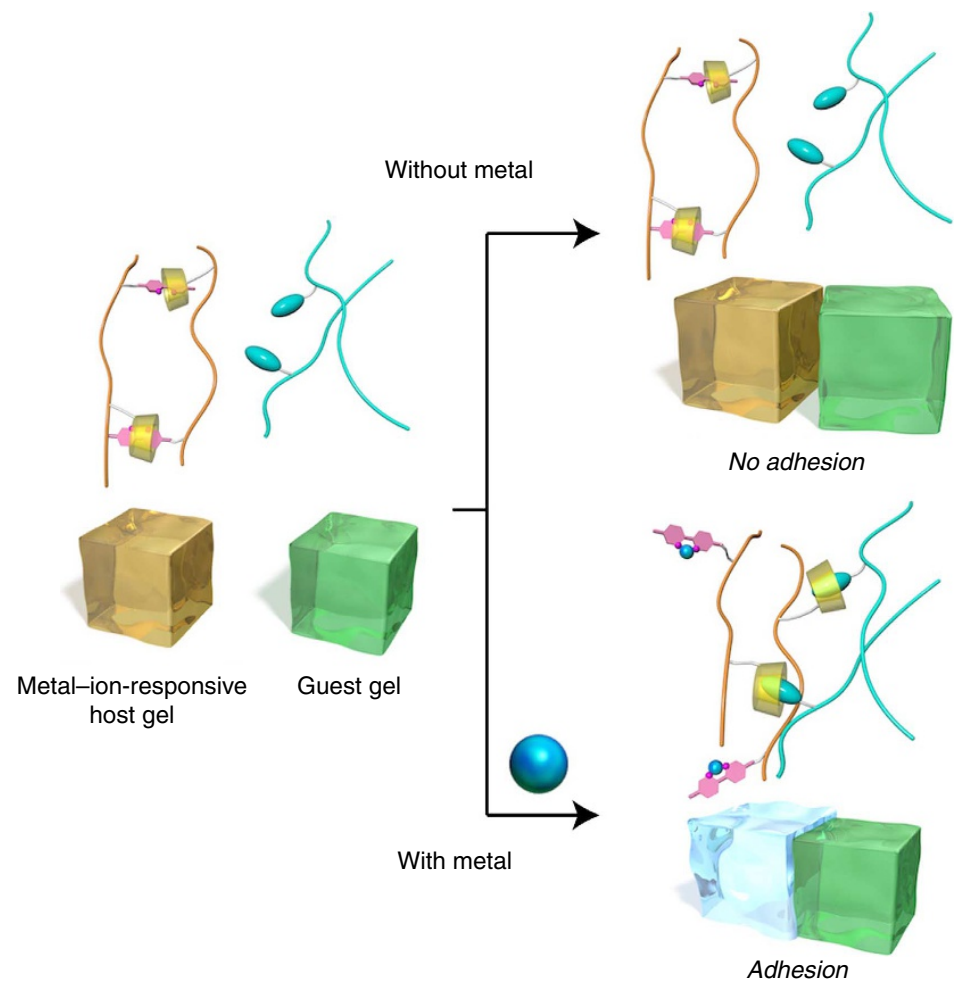

Figure 1 | A metal-ion-responsive adhesive material. (a) Chemical structures of a metal-ion-responsive host gel ( $\beta C D$-bpy gel) and a guest gel $(t$ Bu gel $(x))$. Here, $x$ represents the mol\% content of $N$-tBuAAm groups in the guest gel. (b) Schematic representation of the switching of molecular recognition property of $\beta C D$ via inhibitory inclusion of bpy and its release by complexation to a metal ion. (c) Adhesion of the metal-ion-responsive host gel ( $\beta C D$-bpy gel) to the guest gel (tBu gel $(x)$ ) induced by metal ions as chemical stimuli.

caused from $\beta C D$ 's encapsulation of hydrophobic bpy side chain. These observations indicate that the supramolecular cross-linking $\beta C D$-bpy that had existed in $\beta C D$-bpy gel was dissociated by appropriate external stimuli, which caused the gel to swell.
Property changes of $\beta C D-b p y$ gels depending on metal ions. As efficient formation of $\beta C D$-bpy units in $\beta C D$-bpy gel was demonstrated, the reaction of metal ions with the $\beta C D-b p y$ inclusion complex was investigated. As a model experiment to 
a

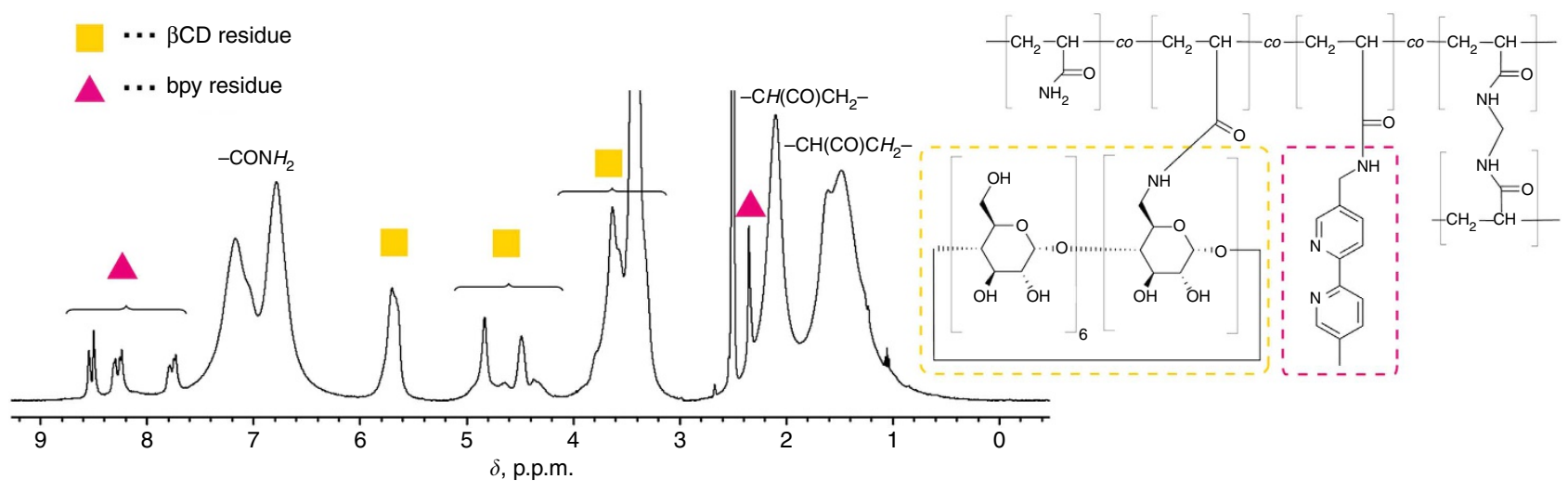

b
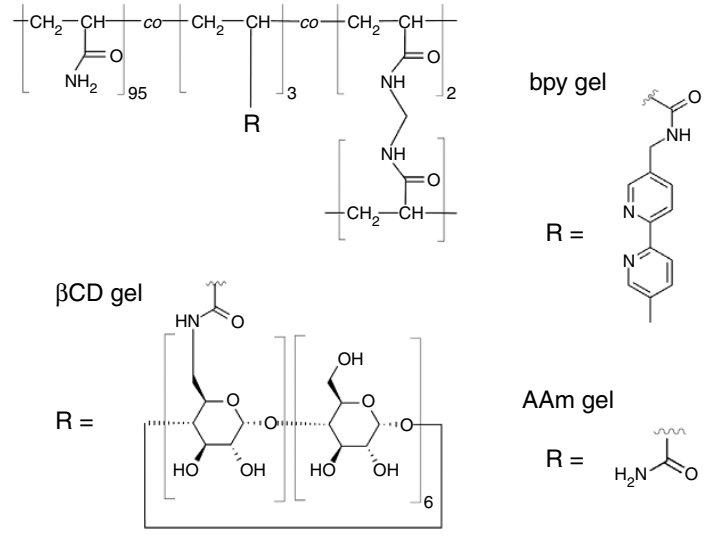

AAm gel

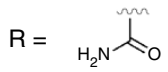

C

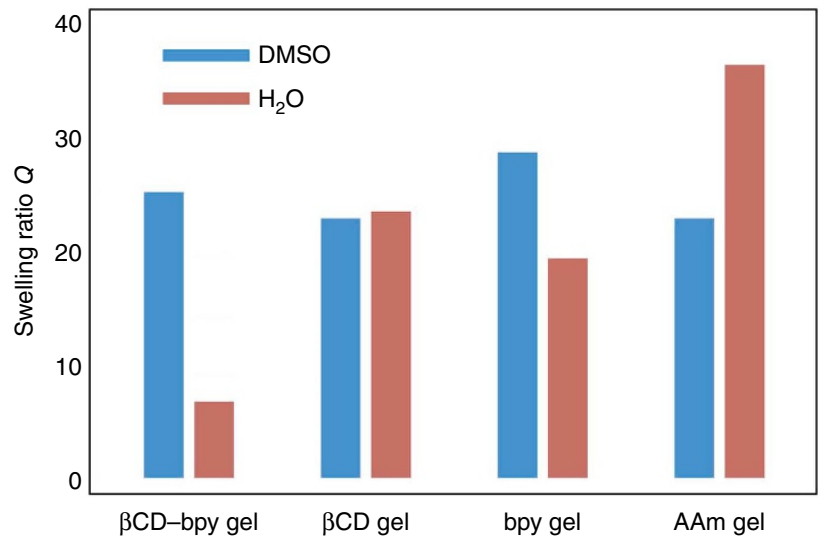

e

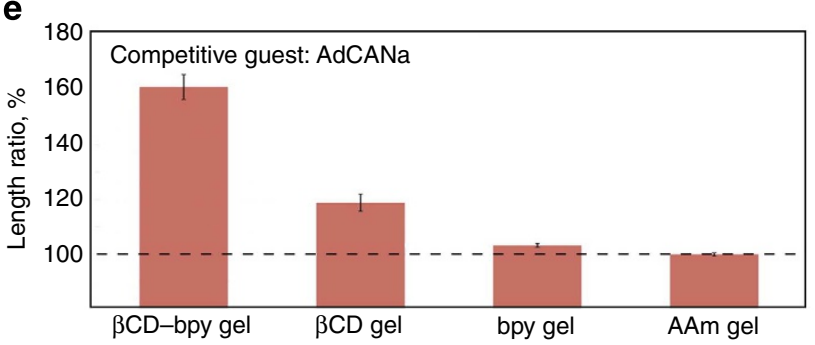

d

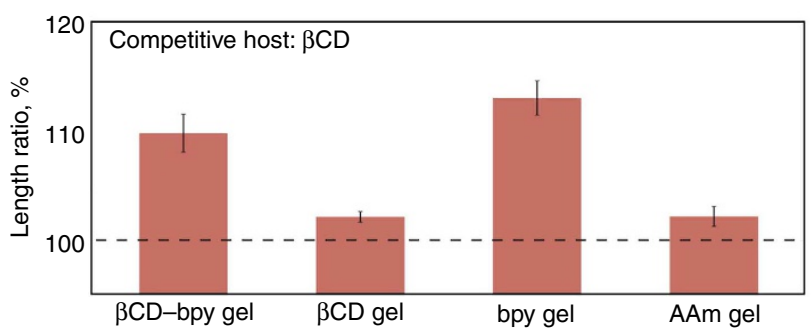

Figure 2 | Characterization of $\beta C D$-bpy gel and supramolecular cross-linking in the gel. (a) FG-MAS NMR of $\beta C D-b p y$ gel swollen with DMSO- $d_{6}$. (b-e) Supramolecular cross-linking in $\beta C D$-bpy gel. (b) Chemical structures of $\beta C D$ gel, bpy gel and AAm gel as reference gels for $\beta C D-b p y$ gel. (c) Swelling ratio $Q$ of gels immersed in $\mathrm{DMSO}$ and $\mathrm{H}_{2} \mathrm{O}$, respectively. Here, $\mathrm{Q}=$ (the weight of a swollen gel)/(the weight of the corresponding dried gel). $(\mathbf{d}, \mathbf{e})$ Length changes of gels by immersing in aqueous solutions of competitive host ( $\beta C D)$ and guest (AdCANa) molecules (10 mM) to disrupt supramolecular cross-linking (error bars, s.e.m. $(n=4)$ ).

obtain detailed information about the reaction, the effect of $\mathrm{Zn}^{2+}$ ion on a $\beta C D$-bpy inclusion complex was examined by ${ }^{1} \mathrm{H}$ NMR measurements in $\mathrm{D}_{2} \mathrm{O}$ solution (Supplementary Fig. 4). On the addition of $\mathrm{Zn}^{2+}$, bpy reacted with $\mathrm{Zn}^{2+}$ and was released from $\beta C D$, which made the cavity of $\beta C D$ free. Subsequent removal of $\mathrm{Zn}^{2}+$ from bpy with a strong metal chelator, ethylenediaminetetraacetic acid tetrasodium salt $(\mathrm{EDTA} \cdot 4 \mathrm{Na})$, regenerated the inclusion complex $\beta C D-b p y$. It was demonstrated that inclusion and release of bpy with $\beta C D$ were reversibly controlled by the presence of the metal ion (Fig. 1b).

The reaction of metal ions with $\beta C D$-bpy gel was investigated by immersing the gel in corresponding metal chloride salt aqueous solutions (Fig. 3). The gel changed its properties reflecting chemical characteristics of different metal-bpy complexes. Figure $3 \mathrm{a}$ shows appearance change of $\beta C D$-bpy gel observed by microscopy after immersing the gel in $\mathrm{CuCl}_{2}$ or $\mathrm{FeCl}_{2}$ aqueous solution. After treatment with $\mathrm{Cu}^{2+}$, the gel became highly swollen up to $c a$. $300 \%$ in length. In the case of $\mathrm{Fe}^{2+}$, the gel was modestly expanded (ca. 120\%) and its colour turned from colourless to red. The red colour is attributed to tris(bpy) complex $\left[\mathrm{Fe}(\mathrm{bpy})_{3}\right]^{2+}$ with metal-to-ligand charge transfer absorption. Figure $3 \mathrm{~b}$ shows the length change of $\beta C D$-bpy gel after treatment with various metal chloride salt solutions. About three equivalents of metal ions were added against the bpy moieties in the gel. The swelling behaviour was very different depending on the type of metal ions. The largest expansion was observed when reacted with $\mathrm{Cu}^{2+}(310 \pm 20 \%)$, while treatment with $\mathrm{Fe}^{2+}$ did not largely expand the gel $(120 \pm 1 \%)$, and the gel was almost the same in length in the case of $\mathrm{Mg}^{2+}(96.3 \pm 0.3 \%)$. Hardness of the gel was also changed on reaction with metal ions. Figure $3 \mathrm{c}$ shows data for tensile strength measurements of $\beta C D$-bpy gel before and after treatment with metal ions. The tensile modulus of the $\beta C D$-bpy gel was $7.2 \pm 0.4 \mathrm{kPa}$, and it was decreased after the reaction with $\mathrm{Cu}^{2+}$ 


\section{a}

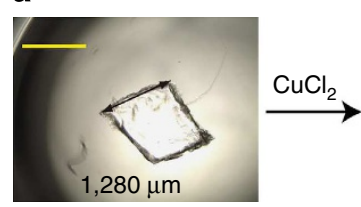

Before

b

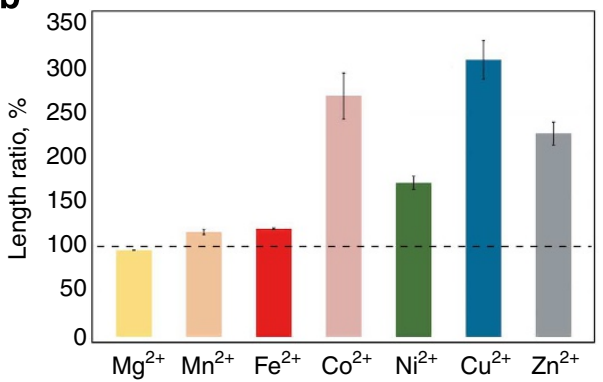

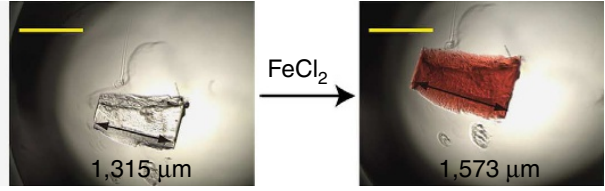

Before

After
C

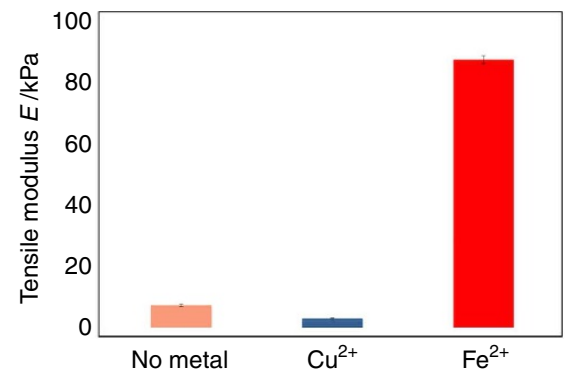

d

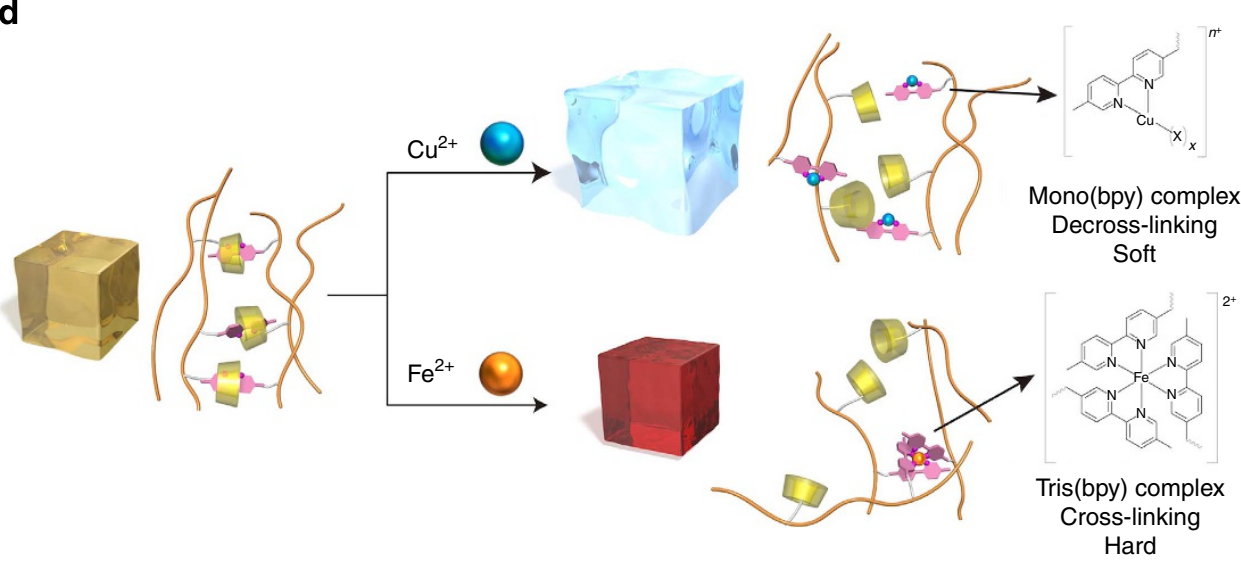

Figure 3 | Reaction of metal ions with $\boldsymbol{\beta C D}$-bpy gel and its property change. (a) Photographs of pieces of $\beta C D$-bpy gel before and after immersion in an aqueous solution of $\mathrm{CuCl}_{2}$ or $\mathrm{FeCl}_{2}$. Scale bar, $1 \mathrm{~mm}$. (b) Length change of $\beta C D$-bpy gel on reaction with various metal salt aqueous solution $\left(\left[\mathrm{MCl}_{2}\right]=2 \mathrm{mM}\left(\mathrm{M}^{2+}=\right.\right.$ metal ion, 3 eq $[/$ bpy $\left.]\right)$. Error bars, s.e.m. $\left.(n=4)\right)$. (c) Tensile modulus of $\beta C D$-bpy gels before and after immersed in an aqueous solution of $\mathrm{CuCl}_{2}$ or $\mathrm{FeCl}_{2}\left(\left[\mathrm{MCl}_{2}\right]=10 \mathrm{mM}\left(\mathrm{M}^{2+}=\right.\right.$ metal ion, 3 eq $\left.[/ \mathrm{bpy}]\right)$. Error bars, s.e.m. $\left.(n=4)\right)$. (d) Schematic representation of decross-linking or cross-linking of $\beta C D$-bpy gels by metal-bpy complex formation.

$(3.0 \pm 0.2 \mathrm{kPa})$. Meanwhile, the tensile modulus was highly increased after the reaction with $\mathrm{Fe}^{2+}(88 \pm 1 \mathrm{kPa})$.

This selectivity is well explained by the difference in metal-toligand ratio of the resulting metal-bpy complexes and their efficiency in cross-linking (Fig. 3d; See also Supplementary Fig. 5 and Supplementary Table 2 for the equilibrium between metalbpy complexes of each element). First, the complexation constant of $\mathrm{Mg}^{2+}$ and 2,2'-bipyridyl is negligible, and that of $\mathrm{Mn}^{2+}$ and bpy is relatively small $\left(\log \beta_{3}=5.9\right.$; ref. 44). These metal ions only slightly interact with the polymer framework of $\beta C D$-bpy gel and thus its size change was small. Second, metal ions such as $\mathrm{Co}^{2+}$, $\mathrm{Ni}^{2+}, \mathrm{Cu}^{2+}$ and $\mathrm{Zn}^{2+}$ mainly form mono(bpy) complex $\left[\mathrm{M}(\text { bpy }) \mathrm{X}_{x}\right]^{n+}\left(\mathrm{X}=\mathrm{Cl}^{-}\right.$or $\left.\mathrm{H}_{2} \mathrm{O}\right)$ when the amount of metal ions is larger than that of bpy (Supplementary Fig. 5) ${ }^{44}$. Thus, the metal ions dissociated the inclusion complex $\beta$ CD-bpy into mono(bpy) metal complex and free $\beta C D$, which decreased in the number of cross-link points. This decross-linking together with an increased swelling pressure brought about by positive charges of metal-bpy complexes made $\beta C D$-bpy gel to largely expand and become soft. And thirdly, $\mathrm{Fe}^{2+}$ ion mainly forms the tris(bpy) complex $\left[\mathrm{Fe}(\mathrm{bpy})_{3}\right]^{2+}$ even when the excess amount of $\mathrm{Fe}^{2+}$ ions against bpy is present in the system (Supplementary Fig. 5$)^{44}$. Thus, the reaction of $\mathrm{Fe}^{2+}$ to $\beta \mathrm{CD}$-bpy gel replaced the cross-links of the inclusion complex $\beta$ CD-bpy with those of the tris(bpy) complex $\left[\mathrm{Fe}(\mathrm{bpy})_{3}\right]^{2+}$. This tris(bpy) complex working as three-way junction in the gel network ${ }^{45}$ counteracted the increasing swelling pressure caused by positive charges and contributed to the stiffness of the gel. To summarize, $\beta \mathrm{CD}-\mathrm{bpy}$ gel behaved as an environmentally responsive material that altered its property based on the characteristics of the metal ions as chemical stimuli.

Metal-ion-responsive adhesion through molecular recognition. We investigated the adhesion property of $\beta C D-b p y$ gel and its metal ion responsiveness. Here, $t$ Bu gels was selected as a subject material to adhere as a model for chemically selective adhesion (Fig. 1a) ${ }^{13}$. It was expected that $\beta C D$-bpy gel ('metal-ionresponsive host gel') adhered to $t \mathrm{Bu}$ gel ('guest gel') via the formation of inclusion complexes $\beta C D-t \mathrm{Bu}$ on the interface of the gels. $t$ Bu gels $(x)$ were prepared by radical copolymerization of AAm, $N$-tert-butylacrylamide ( $t$ BuAAm) and MBAAm in DMSO and used as hydrogels by replacing the solvent with water. Here, $x$ represents the mol\% content of $\mathrm{N}$ - $t \mathrm{BuAAm}$ in feed on the preparation of the gel. Inclusion of $t \mathrm{Bu}$ group within the cavity of $\beta C D$ was tested in a model experiment in aqueous solution, and its binding strength was comparable to that of bpy groups 
(binding constant $K_{\mathrm{a}}$ of $t$ BuAAm to $\beta \mathrm{CD}: 1.0 \times 10^{2} \mathrm{M}^{-1}\left(\mathrm{D}_{2} \mathrm{O}\right.$, 298 K), (Supplementary Figs 6,7)).

The adhesion between $\beta \mathrm{CD}$-bpy gel and $t \mathrm{Bu}$ gel (20), and the effect of metal ions on it were studied (Fig. $4 a-c)$. $\beta C D-b p y$ gel did not adhere to $t \mathrm{Bu}$ gel (20) in the absence of metal ions (Fig. 4b). This is because inclusion ability of $\beta C D$ moieties was suppressed by efficient formation of $\beta C D$-bpy cross-linking in the gel. However, after immersing a piece of $\beta C D-b p y$ gel in $100 \mathrm{mM} \mathrm{CuCl} 2$ aqueous solution for $1 \mathrm{~min}$, it acquired the adhesion ability to that of $t \mathrm{Bu}$ gel (Fig. 4a; Supplementary Movie 1). The adhesion was so strong that the piece of $t \mathrm{Bu}$ gel was lifted up. It was suggested that $\mathrm{Cu}^{2}+$ ions dissociated $\beta C D-$ bpy units and generated free $\beta C D$ that could engage in the formation of inclusion complex with $t \mathrm{Bu}$ groups, and adhesion between the two gels was achieved via the interfacial linking by $\beta C D-t \mathrm{Bu}$ units (Fig. 1c). Furthermore, the removal of $\mathrm{Cu}^{2+}$ from $\beta C D$-bpy gel by immersing in a $100 \mathrm{mM}$ aqueous solution of EDTA $4 \mathrm{Na}$ as a metal ion chelator lost its adhesion ability, which means that reversible switching of adhesion properties in response to metal ions was achieved via control of dissociation and reformation of $\beta C D-b p y$ units in the gel.

Adhesion strength of $\boldsymbol{\beta C D}-\mathbf{b p y}$ gel. The adhesion property of $\beta C D-b p y$ gel showed metal ion selectivity. $\beta C D$-bpy gel immersed in $100 \mathrm{mM} \mathrm{FeCl}$ aqueous solution did not adhere to $t \mathrm{Bu}$ gel (Fig. 4c), which was in clear contrast to the case of $\mathrm{CuCl}_{2}$. Figure $4 \mathrm{~d}$ shows results of tensile adhesion strength measurements between $\beta C D$-bpy gels and $t \mathrm{Bu}$ gels (10) immersed in various kinds of metal chloride salt solutions $\left(\left[\mathrm{MCl}_{2}\right]=10 \mathrm{mM}\right.$ $\left(\mathrm{M}^{2+}=\right.$ metal ion, 3 eq [/bpy]). The pieces of both gels were immersed for $3 \mathrm{~h}$ to reach their equilibrium. See the Methods section for details). $\beta C D$-bpy gel treated with $\mathrm{Co}^{2+}, \mathrm{Ni}^{2+}$, $\mathrm{Cu}^{2+}$ and $\mathrm{Zn}^{2+}$ exhibited adhesion ability to $t \mathrm{Bu}$ gel (10), with the highest value $(1020 \pm 20 \mathrm{~Pa})$ of $\mathrm{Zn}^{2+}$. In contrast, the gels treated with $\mathrm{Mg}^{2+}, \mathrm{Mn}^{2}+$ and $\mathrm{Fe}^{2+}$ did not adhere to it. This selectivity on the kind of metal ions can be explained by the change in gel's physical property as discussed above (Fig. 3d). (1) Metal ions such as $\mathrm{Mg}^{2+}$ and $\mathrm{Mn}^{2+}$ that do not interact at all or only slightly interact with bpy groups had little or no effect on the cross-linking of $\beta C D$-bpy units of $\beta C D$-bpy gel, hence adhesion ability based on $\beta C D$ 's molecular recognition was kept suppressed. (2) Metal ions such as $\mathrm{Co}^{2+}, \mathrm{Ni}^{2+}, \mathrm{Cu}^{2+}$ and $\mathrm{Zn}^{2+}$ that form mono(bpy) complex $\left[\mathrm{M}(\text { bpy }) \mathrm{X}_{x}\right]^{n+}\left(\mathrm{X}=\mathrm{Cl}^{-}\right.$or $\left.\mathrm{H}_{2} \mathrm{O}\right)$ generated free $\beta C D$ in the gel, which gave its adhesion property based on molecular recognition. In addition, decross-linking of network made the gel soft and raised the mobility of the $\beta C D$ moiety on the polymer scaffold, which contributed the efficient formation of $\beta C D-t \mathrm{Bu}$ inclusion complexes on the interface. (3) $\mathrm{Fe}^{2+}$ ion, which mainly forms the tris(bpy) complex $\left[\mathrm{Fe}(\mathrm{bpy})_{3}\right]^{2+}$, dissociated the inclusion complex $\beta \mathrm{CD}-$ bpy into the tris(bpy) iron complex and the $\beta C D$ with its cavity free. Although free $\beta C D$ moieties were generated, the three-way crosslink by tris(bpy) complex made the gel harder over 10-fold (Fig. 3c) and decreased the mobility of $\beta C D$ units, thus its adhesion ability was impaired.

The mechanism of the metal-ion-responsive adhesion based on switching of molecular recognition was further supported by quantitative adhesion measurements. Figure $4 \mathrm{e}$ shows the results of tensile adhesion measurements between $\beta C D$-bpy gel $/ \mathrm{Bu}$ gel (10) immersed in $\mathrm{CuCl}_{2}$ aqueous solutions with different concentrations. $\beta C D$-bpy gel did not exhibit its adhesion property without $\mathrm{Cu}^{2+}$ or with small amount of $\mathrm{Cu}^{2+}$. Meanwhile, the gel immersed in $0.1 \mathrm{mM}$ solution of $\mathrm{CuCl}_{2}$ (about $0.2 \mathrm{eq}$ [/bpy]) showed weak adhesion $(220 \pm 30 \mathrm{~Pa})$ to $t \mathrm{Bu}$ gel, which suggested that the inclusion complexes $\beta C D-b p y$ near the gel's surface were dissociated. The adhesion became stronger as the solution of $\mathrm{CuCl}_{2}$ was more concentrated, and the measured adhesion strength was as high as $1,000 \pm 200 \mathrm{~Pa}$ when immersed in a $100-\mathrm{mM}$ solution of $\mathrm{CuCl}_{2}$. Furthermore, treatment of $\beta C D-b p y$ gel preimmersed in a $10-\mathrm{mM}$ solution of $\mathrm{CuCl}_{2}$ with a $100-\mathrm{mM}$ solution of EDTA - $4 \mathrm{Na}$ lost its adhesion ability to $t \mathrm{Bu}$ gel. This data can be explained by the increase in the number of free $\beta C D$ as the metal complexation reaction with bpy proceeded. Interfacial formation of $\beta C D-t \mathrm{Bu}$ between two gels was supported by quantitative tensile adhesion measurements using $t \mathrm{Bu}$ gels $(x)$ with different mol\% contents of $t \mathrm{Bu}$ groups (Fig. $4 \mathrm{f})^{15}$. $\beta \mathrm{CD}$-bpy gel immersed in $\mathrm{CuCl}_{2}$ solution did not adhere to the AAm gel without $t \mathrm{Bu}$ groups, so there was no macroscopic attractive interaction between polyacrylamide scaffolds of the two gels. The figure shows that $t \mathrm{Bu}$ gel $(x)$ possessing more $t \mathrm{Bu}$ groups gave a higher adhesion strength with $\beta C D-b p y$ gel $(1200 \pm 100 \mathrm{~Pa}$ for $x=25)$, which suggested that adhesion strength is dependent on the number of inclusion complexes formed between the gels. The formation of inclusion complex $\beta C D-t \mathrm{Bu}$ on the interface was further supported by the experiments using $t \mathrm{BuOH}$ as competing guests for $\beta \mathrm{CD}$ (binding constant $K_{\mathrm{a}}$ of $t \mathrm{BuOH}$ to $\beta \mathrm{CD}: 4.8 \times 10 \mathrm{M}^{-1}\left(\mathrm{H}_{2} \mathrm{O}\right.$, $\left.298 \mathrm{~K})^{46}\right)$. The pieces of the two gels did not adhere to each other in the presence of $t \mathrm{BuOH}$ as an inhibitor in the immersing solution $(1,000 \mathrm{mM})$. These experiments demonstrated the importance of $\beta C D$ 's molecular recognition in the adhesion process.

\section{Discussion}

We have reported $\beta C D$-bpy gel as a functional soft material that exerts its adhesion ability via switching of molecular recognition property. The regulation of adhesion based on the $\beta C D$ 's inclusion ability was realized by the effective formation and dissociation of supramolecular cross-linking $\beta C D-b p y$ in response to metal ions as chemical stimuli. Furthermore, $\beta C D$ bpy gel exhibited selectivity on the kind of metal ion in its adhesion, which was derived from the difference in cross-linking efficiency of metal-bpy complexes.

In this system, initially suppressed adhesion property of the material was triggered by external stimuli, and the acquirement of ability was unaccompanied by drastic phase change of the adhesive substances (from liquid to solid, and so on). This makes a clear departure from the mechanism of normal adhesive materials like glues. It is worth noting that chemically selective adhesion by molecular recognition was expressed by the kind of metal ion, which is also a chemical signal. In other words, transduction of two independent chemical signals was achieved in this adhesion system. Using the principle, highly orthogonal macroscopic joining of multiple objects can be created.

The metal-ion-responsive adhesive material can be utilized for many applications. For example, utilizing its reversible adhesion, one could incorporate it into a biomimetic soft robot $^{47}$ that can grab and detach a target object in response to metal ions that are fed either internally (resembling blood circulation) or externally (from environment). Another example would be a smart reinforcement/ masking material that detects metal ions leaked from containers or pipes, and sticks to the weaken part specifically. Furthermore, in combination with other stimuli response ${ }^{13-21}$, medical applications such as nanogels for drug delivery systems ${ }^{48,49}$ would be possible by making use of its selectivity and adhesion strength in wet conditions. We hope that the concept presented here, that is, chemically selective adhesives with chemical stimuli responsiveness, inspire creativity in various fields of science and engineering.

\section{Methods}

General. Unless otherwise noted, solvents and reagents were purchased from Nacalai Tesque Inc., Tokyo Chemical Industries Co. Ltd., Wako Pure Chemical Industries Ltd., Sigma-Aldrich Co. or Merck Ltd. and used without further 
a

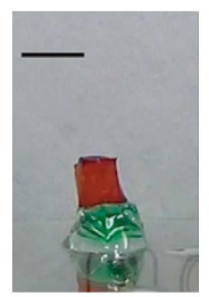

$\beta C D$-bpy gel with $\mathrm{Cu}^{2+}$

tBu gel (20)

b

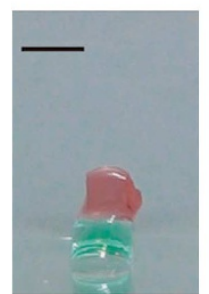

BCD-bpy gel without meta tBu gel (20)

d

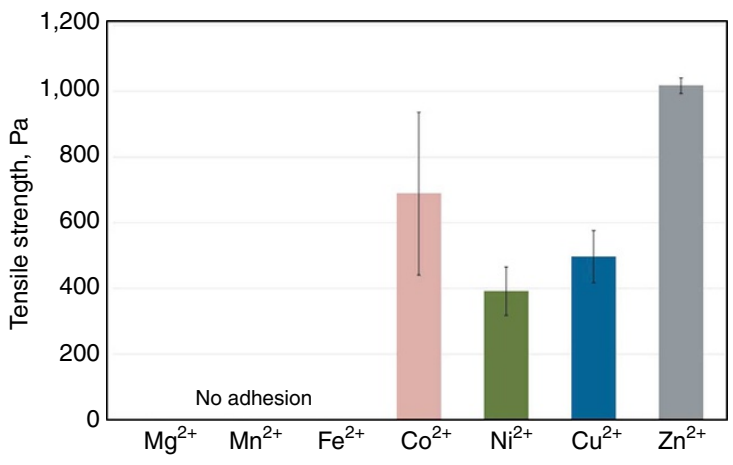

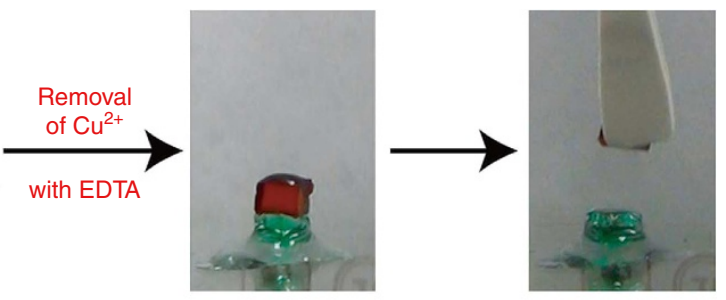

No adhesion

C

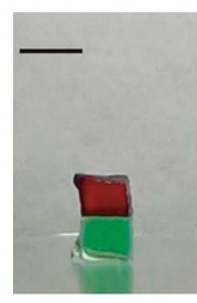

BCD-bpy gel with $\mathrm{Fe}^{2+}$ tBu gel (20)

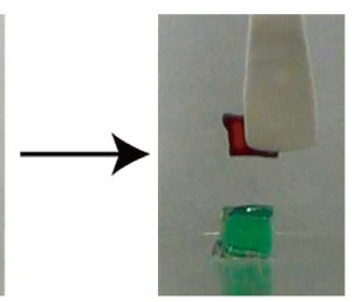

No adhesion

e

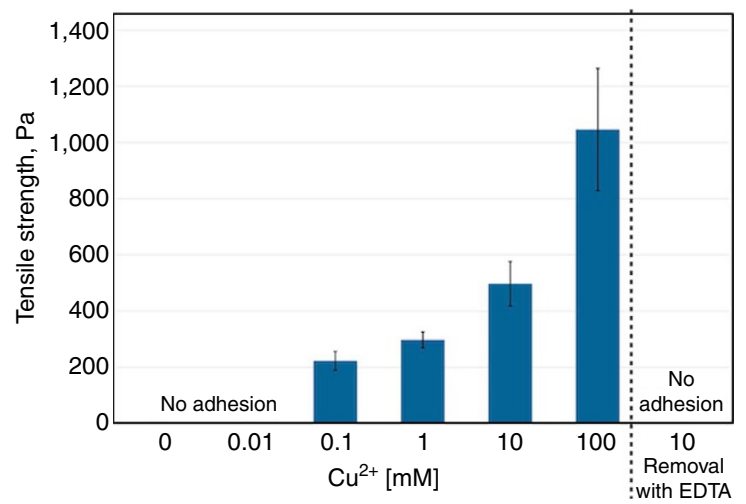

f

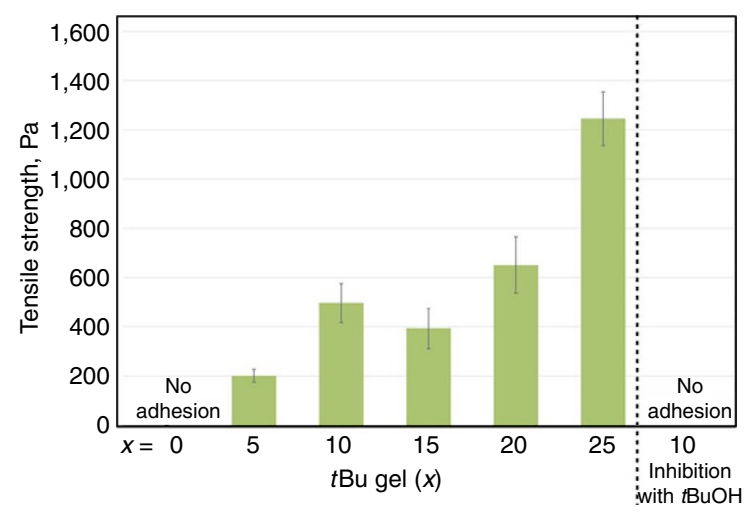

Figure 4 | Metal-ion-responsive adhesion of $\boldsymbol{\beta} \mathbf{C D}$-bpy gel to tBu gels. (a-c) Photographs of metal-ion-responsive adhesion between two pieces of $\beta C D$-bpy gel and tBu gel (20). Each piece of gel was coloured with dyes for clarity ( $\beta C D$-bpy gel; red. tBu gel (20); green). Scale bars, 5 mm. (a) A piece of $\beta C D$-bpy gel immersed in $\mathrm{CuCl}_{2}$ aqueous solution adhered to that of $t \mathrm{Bu}$ gel (20). Removal of $\mathrm{Cu}^{2+}$ from $\beta C D$-bpy gel by immersion in an aqueous solution of EDTA - 4Na switched off its adhesion ability. (b) A piece of $\beta C D$-bpy gel did not adhere to that of tBu gel (20) without immersing in metal solutions. (c) A piece of $\beta C D$-bpy gel immersed in $\mathrm{FeCl}_{2}$ aqueous solution did not adhere to that of $t \mathrm{Bu}$ gel (20). (d-f) Tensile adhesive strength between two pieces of $\beta C D$-bpy gel and $t B u$ gel $(x)$ immersed in metal salt solutions (error bars, s.e.m. $(n=3)$ ). (d) Immersion in various metal salt solutions ( $t \mathrm{Bu}$ gel (10), $\left[\mathrm{MCl}_{2}\right]=10 \mathrm{mM}\left(\mathrm{M}^{2+}=\right.$ metal ion, 3 eq $\left.[/ \mathrm{bpy}]\right)$ ). (e) Immersion in $\mathrm{CuCl}_{2}$ aqueous solutions with different concentrations (tBu gel (10), $\left[\mathrm{CuCl}_{2}\right]=x \mathrm{mM}\left(\mathrm{Cu}^{2+}, 2 x\right.$ eq $\left.[/ \mathrm{bpy}]\right)$ ), and treatment of gels preimmersed in a $10 \mathrm{mM}$ solution of $\mathrm{CuCl}_{2}$ with a solution of EDTA 4 (Na as a metal chelator. $(\mathbf{f}) t \mathrm{Bu}$ gels $(x)$ with different mol\% contents of $t \mathrm{Bu}$ groups $\left(\left[\mathrm{CuCl}_{2}\right]=10 \mathrm{mM}(3 \mathrm{eq}[/ \mathrm{bpy}])\right.$ ) and treatment of gels with an aqueous solution of $\mathrm{tBuOH}$ as an inhibitor of the host-guest complex. 
purification. Water used for the preparation of the aqueous solutions was purified with a Millipore Elix 5 system.

5-Aminomethyl-5'-methyl-2,2' -bipyridine used for the synthesis of 5-acrylamidomethyl- $5^{\prime}$-methyl-2,2' -bipyridine was synthesized from $5,5^{\prime}$-dimethyl-2,2' bipyridine in three steps according to the literature ${ }^{50}$. Mono(6-deoxyacrylamido)$\beta$-cyclodextrin ( $\beta$ CDAAm) was synthesized according to the literature ${ }^{13}$. Elemental analysis (calcd., found for $\mathrm{C}_{45} \mathrm{H}_{78} \mathrm{~N}_{1} \mathrm{O}_{37.5}\left((\beta \mathrm{CDAAm}) \cdot\left(\mathrm{H}_{2} \mathrm{O}\right)_{2.5}\right)$ : $\mathrm{C}(43.83,43.73)$, $\mathrm{H}(6.38,6.23), \mathrm{N}(1.14,1.20)$. $\beta$-Cyclodextrin was purchased from Junsei Chemical Co. Ltd., and recrystallized from water. Elemental analysis: (calcd., found) for $\mathrm{C}_{42} \mathrm{H}_{84} \mathrm{O}_{42}\left((\beta \mathrm{CD}) \cdot\left(\mathrm{H}_{2} \mathrm{O}\right)_{7}\right)$ : $\mathrm{C}(40.00,39.81), \mathrm{H}(6.71,6.57)$. AdCANa was prepared by neutralization of 1-adamantanecarboxylic acid (Tokyo Chemical Industries Co. Ltd.) with equivalent amount of $\mathrm{NaOH}$.

The ${ }^{1} \mathrm{H}$ NMR and ${ }^{13} \mathrm{C}$ NMR spectra were recorded on a JEOL ECA-500 or a JEOL ECS-400 NMR spectrometers. Residual solvent signals were used for calibration of ${ }^{1} \mathrm{H}$ NMR (DMSO- $d_{6}\left(\delta 2.50\right.$ p.p.m.) and $\mathrm{D}_{2} \mathrm{O}\left(4.77\right.$ p.p.m.)) and ${ }^{13} \mathrm{C}$ NMR (DMSO- $d_{6}(\delta 39.52$ p.p.m. $\left.)\right)^{51}$. The solid-state ${ }^{1} \mathrm{H}$ FG-MAS NMR spectra were recorded on a JEOL ECA-400 NMR spectrometer. Sample spinning rate was $7 \mathrm{kHz}$. Electrospray ionization-time-of-flight mass spectrometry spectrum was measured using Orbital XL (Thermo Fisher Scientific). Sizes of the gels were measured using an EVOS AME i2111 digital inverted microscope (Life Technologies). Tensile adhesion strength and mechanical properties of gels were measured by a Yamaden RE2-33005C creep metre.

Synthesis of bpyAAm. To a Schlenk flask filled with argon gas were added 5-aminomethyl-5' -methyl-2,2' -bipyridine ( $100.5 \mathrm{mg}, 0.504 \mathrm{mmol}, 1.0 \mathrm{eq})$, dehydrated tetrahydrofuran $(4 \mathrm{ml})$ and triethylamine $\left(\mathrm{Et}_{3} \mathrm{~N} ; 0.14 \mathrm{ml}, 1.00 \mathrm{mmol}\right.$, $2.0 \mathrm{eq})$. The mixture was stirred at $0^{\circ} \mathrm{C}$ and acryloyl chloride $(61 \mu \mathrm{l}, 0.75 \mathrm{mmol}, 1.5$ eq) was added dropwise. The reaction mixture was warmed to room temperature and stirred for $2 \mathrm{~h}$. The mixture was filtrated, and the filtrate was concentrated to dryness under reduced pressure. The crude product was purified using flash column chromatography (silica gel, eluent: $\mathrm{CHCl}_{3} / \mathrm{CH}_{3} \mathrm{OH}$ ). 5-Acrylamidomethyl$5^{\prime}$-methyl-2,2'-bipyridine was obtained as a colourless solid $(85.4 \mathrm{mg}, 67 \%)$. See Supplementary Figs 8,9 for ${ }^{1} \mathrm{H}$ NMR and ${ }^{13} \mathrm{C}$ NMR spectra, respectively. M.p.: $167.5-168.0^{\circ} \mathrm{C} ;{ }^{1} \mathrm{H} \mathrm{NMR}\left(\mathrm{CDCl}_{3}, 500 \mathrm{MHz}, 298 \mathrm{~K}\right): \delta 8.55(1 \mathrm{H}, \mathrm{d}, J=2.3 \mathrm{~Hz}), 8.49$ $(1 \mathrm{H}, \mathrm{d}, J=2.3 \mathrm{~Hz}), 8.28(1 \mathrm{H}, \mathrm{d}, J=8.0 \mathrm{~Hz}), 8.23(1 \mathrm{H}, \mathrm{d}, J=8.0 \mathrm{~Hz}), 7.72(1 \mathrm{H}, \mathrm{dd}$, $J=8.0,2.3 \mathrm{~Hz}), 7.61(1 \mathrm{H}$, ddd, $J=8.0,2.3,0.6 \mathrm{~Hz}), 6.35(1 \mathrm{H}, \mathrm{dd}, J=16.9,1.4 \mathrm{~Hz})$, $6.26(1 \mathrm{H}, \mathrm{br}), 6.15(1 \mathrm{H}, \mathrm{dd}, J=16.9,10.3 \mathrm{~Hz}), 5.69(1 \mathrm{H}, \mathrm{dd}, J=10.3,1.4 \mathrm{~Hz}), 4.56$ $(2 \mathrm{H}, \mathrm{d}, J=5.7 \mathrm{~Hz}), 2.39(3 \mathrm{H}, \mathrm{s}) ;{ }^{13} \mathrm{C} \mathrm{NMR}\left(\mathrm{CDCl}_{3}, 126 \mathrm{MHz}, 298 \mathrm{~K}\right): \delta 165.6$, $155.7,153.3,149.6,148.6,137.5,136.6,133.6,133.5,130.4,127.3,120.7,120.7,40.9$, 18.4; HRMS $(\mathrm{m} / \mathrm{z}):[\mathrm{M}+\mathrm{H}]^{+}$calcd. for $\mathrm{C}_{15} \mathrm{H}_{16} \mathrm{~N}_{3} \mathrm{O}, 254.1288$; found, 254.1295; Elemental analysis (calcd., found for $\mathrm{C}_{15} \mathrm{H}_{15.2} \mathrm{~N}_{3} \mathrm{O}_{1.1}\left((\right.$ bpyAAm) $\left.\left.)\left(\mathrm{H}_{2} \mathrm{O}\right)_{0.1}\right)\right)$ : C (70.62, 70.49), H $(6.01,5.94), \mathrm{N}(16.45,16.21)$.

Preparation of $\boldsymbol{\beta C D}$-bpy gel. A representative procedure: to a sample tube $(\phi 19 \mathrm{~mm})$ was added $1,000 \mu \mathrm{l}$ of DMSO solution containing AAm $(1,840 \mu \mathrm{mol})$, BCDAAm $(60 \mu \mathrm{mol})$, bpyAAm $(60 \mu \mathrm{mol})$, MBAAm $(40 \mu \mathrm{mol}$; total monomer concentration: $2.00 \mathrm{M})$ and AIBN $(20 \mu \mathrm{mol})$. The solution was deaerated by bubbling argon gas through it for $30 \mathrm{~min}$. The mixture was heated in $65^{\circ} \mathrm{C}$ oven for $24 \mathrm{~h}$ to form a gel. The gel was washed with DMSO (soaked and shaken in DMSO solvent) for $12 \mathrm{~h}$ and this was repeated four times, to give a gel swollen with DMSO $(4,046 \mathrm{mg})$. After that the gel was washed with $\mathrm{H}_{2} \mathrm{O}$ (4 days, $\mathrm{H}_{2} \mathrm{O}$ was replaced once a day) and used as a hydrogel $(1,081 \mathrm{mg})$. The swelling ratio in Fig. $2 \mathrm{~b}$ was calculated based on the weight of hydrogels after freeze dried. See Fig. 2a for FG-MAS ${ }^{1} \mathrm{H}$ NMR spectrum of the gel immersed in DMSO- $d_{6}$. Elemental analysis of the hydrogel after freeze dried: (calcd., found) for $\mathrm{C}_{436.4} \mathrm{H}_{779.6} \mathrm{~N}_{108} \mathrm{O}_{221.8}$ $\left((\mathrm{AAm})_{92.8}(\text { (BCDAAm })_{2.2}(\text { bpyAAm })_{3.0}(\mathrm{MBAAm})_{2.0}\left(\mathrm{H}_{2} \mathrm{O}\right)_{45}\right)$ : C $(47.27,47.28), \mathrm{H}$ $(7.05,6.98), \mathrm{N}(13.64,13.87)$.

Preparation of $\beta C D$ gel. $\beta C D$ gel was prepared according to a similar procedure for $\beta C D$-bpy gel, using 1,000 $\mu \mathrm{l}$ DMSO solution of AAm $(1,900 \mu \mathrm{mol}), \beta C D A A m$ $(60 \mu \mathrm{mol})$, MBAAm $(40 \mu \mathrm{mol})$ (total monomer concentration: $2.00 \mathrm{M})$ and AIBN $(20 \mu \mathrm{mol})$. The weights of a $\beta \mathrm{CD}$ gel swollen in DMSO and $\mathrm{H}_{2} \mathrm{O}$ were 3,527 and $3,632 \mathrm{mg}$, respectively.

Preparation of bpy gel. Bpy gel was prepared according to a similar procedure for $\beta C D$-bpy gel, using $1,000 \mu \mathrm{l}$ DMSO solution of AAm $(1,900 \mu \mathrm{mol})$, bpyAAm $(60 \mu \mathrm{mol})$, MBAAm $(40 \mu \mathrm{mol})$ (total monomer concentration: $2.00 \mathrm{M})$ and AIBN $(20 \mu \mathrm{mol})$. The weights of a bpy gel swollen in DMSO and $\mathrm{H}_{2} \mathrm{O}$ were 3,133 and $2,114 \mathrm{mg}$, respectively.

Preparation of AAm gel. AAm gel was prepared according to a similar procedure for $\beta C D$-bpy gel, using 1,000 $\mu$ l DMSO solution of AAm (1,960 $\mu \mathrm{mol})$, MBAAm $(40 \mu \mathrm{mol})$ (total monomer concentration: $2.00 \mathrm{M})$ and AIBN $(20 \mu \mathrm{mol})$. The weights of an AAm gel swollen in DMSO and $\mathrm{H}_{2} \mathrm{O}$ were 2,463 and $3,922 \mathrm{mg}$, respectively.

Preparation of $\mathbf{t B u}$ gels $(\boldsymbol{x})$. $t \mathrm{Bu}$ gels $(x)$ were prepared according to a similar procedure for $\beta C D$-bpy gel, using 1,000 $\mu$ l DMSO solution of AAm (1980 $20 x \mu \mathrm{mol}), t$ BuAAm $(20 x \mu \mathrm{mol})$, MBAAm $(20 \mu \mathrm{mol})$ (total monomer concentration: $2.00 \mathrm{M})$ and AIBN $(20 \mu \mathrm{mol})$. The weights of a $t$ Bu gel (10) swollen in DMSO and $\mathrm{H}_{2} \mathrm{O}$ were 5,125 and $6,155 \mathrm{mg}$, respectively.

Observation of gels reacted with competitive hosts/guests. $\beta C D$-bpy gel was cut into $c a .1 \times 1 \times 1 \mathrm{~mm}$ pieces. Each piece was placed in a cylindrical well $(\phi$ $6.4 \mathrm{~mm} \times 10 \mathrm{~mm}$, polystyrene), $60 \mu \mathrm{l}$ of $\mathrm{H}_{2} \mathrm{O}$ (depth $\sim 2 \mathrm{~mm}$ ) was added. Each piece of the gel was observed by the microscope and its size was measured. After that, $240 \mu \mathrm{l}$ of a $12.5 \mathrm{mM}$ aqueous solution of a competitive host $(\beta C D)$ or a competitive guest (AdCANa: 1-adamantanecarboxylic acid sodium salt) was added to the wells (total $300 \mu \mathrm{l}, 10.0 \mathrm{mM}, 3 \mu \mathrm{mol}, \sim 50 \mathrm{eq}$ [/bpy or $\beta C D]$ ). Each piece of the gel was observed by the microscope $12 \mathrm{~h}$ after immersion and its size was measured. The experiments were performed at $25^{\circ} \mathrm{C}$.

Observation of gels reacted with metal salts. $\beta C D$-bpy gel was cut into $\mathrm{ca}$. $1 \times 1 \times 1 \mathrm{~mm}$ pieces. Each piece was placed in a cylindrical well $(\phi 6.4 \times 10 \mathrm{~mm}$, polystyrene), $80 \mu \mathrm{l}$ of $\mathrm{H}_{2} \mathrm{O}$ (depth $\sim 2.5 \mathrm{~mm}$ ) was added. Each piece of the gel was observed by the microscope and its size was measured. After that, $16 \mu \mathrm{l}$ of $10 \mathrm{mM}$ aqueous solution of $\mathrm{MCl}_{2}(\mathrm{M}=\mathrm{Mg}, \mathrm{Mn}, \mathrm{Fe}, \mathrm{Co}, \mathrm{Ni}, \mathrm{Cu}$ or $\mathrm{Zn})$ was added to the wells (total $96 \mu \mathrm{l}, 1.7 \mathrm{mM}, 0.16 \mu \mathrm{mol}, \sim 3 \mathrm{eq}$ [/bpy]). Each piece of the gel was observed by the microscope $12 \mathrm{~h}$ after immersion, and its size was measured. The experiments were performed at $25^{\circ} \mathrm{C}$.

Tensile modulus measurements of $\beta C D-b p y$ gel and $t B u$ gel. A representative procedure: $\beta C D$-bpy gel was cut out into $c a .4 \times 2 \times 10 \mathrm{~mm}$ cuboids using a razor. Weight of each piece of the $\beta C D$-bpy gel was measured (ca. $80 \mathrm{mg}$, bpy $32 \mu \mathrm{mol}$ ). Each piece of the $\beta C D$-bpy gel and the $t \mathrm{Bu}$ gel was immersed in $10 \mathrm{mM} \mathrm{CuCl} 2$ aqueous solution (ca. $0.8 \mathrm{ml}$, amount of $\mathrm{Cu}^{2+} 2-3$ eq [/bpy]) for $3 \mathrm{~h}$. After immersion, the tensile strength measurement was performed using a creep metre (Yamaden, RE2-33005C. Load cell: $2 \mathrm{~N}$ (10-fold amplified sensitivity)). Sides of two pieces of the gel was clipped on the jig so that the tensile direction was vertical to its $4 \times 2 \mathrm{~mm}$ face. The size of the sectional area was measured by a vernier caliper. Tensile stress-strain curves were measured as being pulled at a speed of $0.1 \mathrm{~mm} \mathrm{~s}^{-1}$. Young's moduli of the gels were obtained from the initial gradients of the measurements.

Qualitative adhesion tests of $\boldsymbol{\beta C D}$-bpy gels and tBu gels. A representative procedure: $\beta C D$-bpy gels and $t$ Bu gels (20) were cut out into $c a .5 \times 5 \times 5 \mathrm{~mm}$ cubes using a razor. For clarity, pieces of $\beta C D$-bpy gel were dyed by immersing in ca. $40 \mathrm{ml}$ of an aqueous solution of a red food colouring dye (containing $85 \mathrm{wt} \%$ of dextrins and $15 \mathrm{wt} \%$ of New Coccin, [New Coccin] $=0.05 \mathrm{mM}$ ) and those of $t$ Bu gel (20) were dyed by immersing in ca. $40 \mathrm{ml}$ of an aqueous solution of a green food colouring dye (containing $88 \mathrm{wt} \%$ of dextrins, $8.4 \mathrm{wt} \%$ of Tartrazine and $3.6 \mathrm{wt} \%$ of Brilliant Blue FCF, (Tartrazine + Brilliant Blue FCF) $=0.10 \mathrm{mM}$ ), respectively. Surfaces of both gels were rinsed with $\mathrm{H}_{2} \mathrm{O}$ before use. A piece of $t \mathrm{Bu}$ gel (20) was put on a glass petri dish. A piece of $\beta C D$-bpy gel was stacked on top of that of $t \mathrm{Bu}$ gel (20), and lifted up again after waiting for several seconds, showing that no adhesion between them. Next, the piece of $\beta C D$-bpy gel was put in $5 \mathrm{ml}$ of a $100 \mathrm{mM}$ aqueous solution of $\mathrm{CuCl}_{2}$ for $1 \mathrm{~min}$. The piece of $\beta \mathrm{CD}$-bpy gel immersed in $\mathrm{CuCl}_{2}$ solution was stacked on top of that of $t \mathrm{Bu}$ gel (20), and lifted up again after waiting for several seconds, showing that the adhesion was so strong that the piece of $t \mathrm{Bu}$ gel (20) was able to be picked up. After separating two gels using tweezers, the piece of $\beta C D$-bpy gel was immersed in $5 \mathrm{ml}$ of a $100 \mathrm{mM}$ aqueous solution of EDTA $4 \mathrm{Na}$ for $1 \mathrm{~min}$. The piece of $\beta \mathrm{CD}$-bpy gel did not show adhesive ability to that of $t \mathrm{Bu}$ gel (20) any more (see also Fig. 4a-c and Supplementary Movie 1).

Tensile adhesion strength measurements. A representative procedure: $\beta C D$-bpy gel and $t$ Bu gel (10) were cut out into $c a .5 \times 2 \times 10 \mathrm{~mm}$ cuboids using a razor. Weight of the $\beta C D-b p y$ gel was measured ( $c a .100 \mathrm{mg}$, bpy $40 \mu \mathrm{mol})$. Both $\beta C D$-bpy gel and $t \mathrm{Bu}$ gel $(10)$ were immersed in a $10-\mathrm{mM}$ aqueous solution of $\mathrm{CuCl}_{2}$ (ca. $1.2 \mathrm{ml}$, amount of $\mathrm{Cu}^{2+} 3 \mathrm{eq} \mathrm{[/bpy])}$ for $3 \mathrm{~h}$. After immersion, the tensile strength measurement was performed using a creep metre (Yamaden, RE2-33005C. Load cell: $2 \mathrm{~N}$ (10-fold amplified sensitivity)). Each side of two gels was clipped on the jig, and contacted on a $5 \times 2 \mathrm{~mm}$ face. The size of the adhesion face was measured by a vernier caliper. Tensile adhesion strength at rupture was measured as being pulled at a speed of $0.1 \mathrm{~mm} \mathrm{~s}^{-1}$.

\section{References}

1. Brockmann, W., Geiß, P. L., Klingen, J. \& Schröder, B. Adhesive Bonding (Wiley-VCH Verlag GmbH \& Co. KGaA, 2009).

2. Adams, R. D. Adhesive Bonding (Woodhead Publishing Ltd., 2005).

3. Onusseit, H. et al. Adhesives, 1 General in Ullmann's Encyclopedia of Industrial Chemistry (Wiley-VCH Verlag GmbH \& Co. KGaA, 2010).

4. Liu, M. \& Jiang, L. Switchable adhesion on liquid/solid interfaces. Adv. Funct. Mater. 20, 3753-3764 (2010).

5. Kamperman, M. \& Synytska, A. Switchable adhesion by chemical functionality and topography. J. Mater. Chem. 22, 19390-19401 (2012).

6. Kelley, E. G., Albert, J. N. L., Sullivan, M. O. \& Epps, III T. H. Stimuliresponsive copolymer solution and surface assemblies for biomedical applications. Chem. Soc. Rev. 42, 7057-7071 (2013). 
7. Wang, T., Canetta, E., Weerakkody, T. G. \& Keddie, J. L. pH Dependence of the properties of waterborne pressure-sensitive adhesives containing acrylic acid. ACS Appl. Mater. Interfaces 1, 631-639 (2009).

8. Boyne, J. M., Millan, E. J. \& Webster, I. Peeling performance of a novel light switchable pressure-sensitive adhesive. Int. J. Adhes. Adhes. 21, 49-53 (2001).

9. Svetushkina, E., Puretskiy, N., Ionov, L., Stamm, M. \& Synytska, A. A comparative study on switchable adhesion between thermoresponsive polymer brushes on flat and rough surfaces. Soft Matter 7, 5691-5696 (2011).

10. Xue, L. et al. Reversible adhesion switching of porous fibrillar adhesive pads by humidity. Nano Lett. 13, 5541-5548 (2013).

11. Gillies, A. G., Kwak, J. \& Fearing, R. S. Controllable particle adhesion with a magnetically actuated synthetic gecko adhesive. Adv. Funct. Mater. 23, 3256-3261 (2013).

12. Bowden, N. B., Weck, M., Choi, I. S. \& Whitesides, G. M. Molecule-mimetic chemistry and mesoscale self-assembly. Acc. Chem. Res. 34, 231-238 (2001).

13. Harada, A., Kobayashi, R., Takashima, T., Hashidzume, A. \& Yamaguchi, H. Macroscopic self-assembly through molecular recognition. Nat. Chem. 3, 34-37 (2011).

14. Yamaguchi, H., Kobayashi, R., Takashima, T., Hashidzume, A. \& Harada, A Self-assembly of gels through molecular recognition of cyclodextrins: shape selectivity for linear and cyclic guest molecules. Macromolecules 44, 2395-2399 (2011).

15. Zheng, Y., Hashidzume, A., Takashima, T., Yamaguchi, H. \& Harada, A. Macroscopic observations of molecular recognition: discrimination of the substituted position on the naphthyl group by polyacrylamide gel modified with $\beta$-cyclodextrin. Langmuir 27, 13790-13795 (2011).

16. Zheng, Y., Hashidzume, A., Takashima, T., Yamaguchi, H. \& Harada, A. Temperature-sensitive macroscopic assembly based on molecular recognition. ACS Macro Lett. 1, 1083-1085 (2012).

17. Hashidzume, A., Zheng, Y., Takashima, T., Yamaguchi, H. \& Harada, A. Macroscopic self-assembly based on molecular recognition: effect of linkage between aromatics and the polyacrylamide gel scaffold, amide versus ester. Macromolecules 46, 1939-1947 (2013).

18. Yamaguchi, H. et al. Photoswitchable gel assembly based on molecular recognition. Nat. Commun. 3, 603 (2012).

19. Zheng, Y., Hashidzume, A. \& Harada, A. pH-Responsive self-assembly by molecular recognition on a macroscopic scale. Macromol. Rapid Commun. 34, 1062-1066 (2013).

20. Zheng, Y., Hashidzume, A., Takashima, Y., Yamaguchi, H. \& Harada, A. Switching of macroscopic molecular recognition selectivity using a mixed solvent system. Nat. Commun. 3, 831 (2012).

21. Kobayashi, Y., Takashima, Y., Hashidzume, A., Yamaguchi, H. \& Harada, A. Reversible self-assembly of gels through metal-ligand interactions. Sci. Rep. 3, 1243 (2013).

22. Bertini, I., Gray, H. B., Stiefel, E. I. \& Valentine, J. S. Biological Inorganic Chemistry: Structure and Reactivity (University Science Books, 2006).

23. Champin, B., Mobian, P. \& Sauvage, J.-P. Transition metal complexes as molecular machine prototypes. Chem. Soc. Rev. 36, 358-366 (2007).

24. Nabeshima, T. Construction of cooperative and responsive supramolecular systems for molecular functional modulation. Bull. Chem. Soc. Jpn. 83, 969-991 (2010).

25. Tashiro, S. \& Shionoya, M. Stimuli-responsive synthetic metallopeptides. Chem. Lett. 42, 456-462 (2013).

26. Piepenbrock, M.-O. M., Lloyd, G. O., Clarke, N. \& Steed, J. W. Metal- and anion-binding supramolecular gels. Chem. Rev. 110, 1960-2004 (2010).

27. Tam, A. Y.-Y. \& Yam, V. W.-W. Recent advances in metallogels. Chem. Soc Rev. 42, 1540-1567 (2013).

28. Iseda, K., Kokado, K. \& Sada, K. Design and function of smart polymer gels based on ion recognition. React. Funct. Polym. 73, 951-957 (2013).

29. Chujo, Y., Sada, K. \& Saegusa, T. Iron(II) bipyridyl-branched polyoxazoline complex as a thermally reversible hydrogel. Macromolecules 73, 6315-6319 (1993).

30. Kawano, S., Fujita, N. \& Shinkai, S. A coordination gelator that shows a reversible chromatic change and sol-gel phase-transition behavior upon oxidative/reductive stimuli. J. Am. Chem. Soc. 126, 8592-8593 (2004).

31. Weng, W., Beck, J. B., Jamieson, A. M. \& Rowan, S. J. Understanding the mechanism of gelation and stimuli-responsive nature of a class of metallosupramolecular gels. J. Am. Chem. Soc. 128, 11663-11672 (2006).

32. Holten-Andersen, N. et al. $\mathrm{pH}$-induced metal-ligand cross-links inspired by mussel yield self-healing polymer networks with near-covalent elastic moduli. Proc. Natl Acad. Sci. USA 108, 2651-2655 (2011).

33. Harada, A. Supramolecular Polymer Chemistry (Wiley-VCH Verlag GmbH \& Co. KGaA, 2011).

34. De Greef, T. F. A. et al. Supramolecular polymerization. Chem. Rev. 109, 5687-5754 (2009)

35. Aida, T., Meijer, E. W. \& Stupp, S. I. Functional supramolecular polymers Science 335, 813-817 (2012).
36. Schmidt, B. V. K. J., Hetzer, M., Ritter, H. \& Barner-Kowollik, C. Complex macromolecular architecture design via cyclodextrin host/guest complexes. Prog. Polym. Sci. 39, 235-249 (2014).

37. Zhang, J. et al. One-step fabrication of supramolecular microcapsules from microfluidic droplets. Science 335, 690-694 (2012).

38. Appel, E. A. et al. Ultrahigh-water-content supramolecular hydrogels exhibiting multistimuli responsiveness. J. Am. Chem. Soc. 134, 11767-11773 (2012).

39. Nakahata, M., Takashima, Y., Yamaguchi, H. \& Harada, A. Redox-responsive self-healing materials formed from host-guest polymers. Nat. Commun. 2, 511 (2011).

40. Takashima, Y. et al. Expansion-contraction of photoresponsive artificial muscle regulated by host-guest interactions. Nat. Commun. 3, 1270 (2012).

41. Kakuta, T. et al. Preorganized hydrogel: Self-healing properties of supramolecular hydrogels formed by polymerization of host-guest-monomers that contain cyclodextrins and hydrophobic guest groups. Adv. Mater. 25, 2849-2853 (2013).

42. Rivas, B. L. \& Moreno-Villoslada, I. Chelation properties of polymer complexes of poly(acrylic acid) with poly(acrylamide), and poly(acrylic acid) with poly(N,N-dimethylacrylamide). Macromol. Chem. Phys. 199, 1153-1160 (1998).

43. Liu, Y., Zhao, Y.-L., Zhang, H.-Y., Yang, E.-C. \& Guan, X.-D. Binding ability and assembly behavior of $\beta$-cyclodextrin complexes with $2,2^{\prime}$-dipyridine and 4,4'-dipyridine. J. Org. Chem. 69, 3383-3390 (2004).

44. McBryde, W.A. E. A Critical Review of Equilibrium Data for Proton- and Metal Complexes of 1,10-Phenanthroline, 2,2'-Bipyridyl and Related Compounds (Pergamon Press Ltd., 1978).

45. Skrzeszewska, P. J. et al. Physical gels of telechelic triblock copolymers with precisely defined junction multiplicity. Soft Matter 5, 2057-2062 (2009).

46. Matsui, Y. \& Mochida, K. Binding forces contributing to the association of cyclodextrin to alcohol in an aqueous solution. Bull. Chem. Soc. Jpn $\mathbf{5 2}$ 2808-2814 (1979).

47. Bauer, S. et al. 25th anniversary article: a soft future: From robots and sensor skin to energy harvesters. Adv. Mater. 26, 149-162 (2014).

48. Oh, J. K., Drumright, R., Siegwart, D. J. \& Matyjaszewski, K. The development of microgels/nanogels for drug delivery applications. Prog. Polym. Sci. 33, 448-477 (2008).

49. Concheiro, A. \& Alvarez-Lorenzo, C. Chemically cross-linked and grafted cyclodextrin hydrogels: From nanostructures to drug-eluting medical devices. Adv. Drug Delivery Rev. 65, 1188-1203 (2013).

50. Heck, R., Dumarcay, F. \& Marsura, A. New scaffolds for supramolecular chemistry: upper-rim fully tethered 5-methyleneureido- $5^{\prime}$-methyl-2,2' bipyridyl cyclodextrins. Chem. Eur. J. 8, 2438-2445 (2002).

51. Gottlieb, H. E., Kotlyar, V. \& Nudelman, A. NMR chemical shifts of common laboratory solvents as trace impurities. J. Org. Chem. 62, 7512-7515 (1997).

\section{Acknowledgements}

We appreciate Dr Naoya Inazumi (Osaka University) for the FG-MAS NMR measurements and Mr. Masaki Nakahata (Osaka Univeristy) for the tensile modulus measurements. This work was supported by the 'Core Research for Evolutional Science and Technology' program of the Japan Science and Technology Agency.

\section{Author contributions}

T.N. and A. Harada conceived the project. T.N. designed and performed the experiments. T.N., Y.T. and A. Harada analysed the data and co-wrote the paper. A. Hashidzume and H.Y. contributed to discussion of the result.

\section{Additional information}

Supplementary Information accompanies this paper at http://www.nature.com/ naturecommunications

Competing financial interests: The authors declare no competing financial interests

Reprints and permission information is available online at http://npg.nature.com/ reprintsandpermissions/

How to cite this article: Nakamura, T. et al. A metal-ion-responsive adhesive material via switching of molecular recognition properties. Nat. Commun. 5:4622 doi: $10.1038 /$ ncomms5622 (2014).

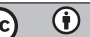

This work is licensed under a Creative Commons Attribution 4.0 International License. The images or other third party material in this article are included in the article's Creative Commons license, unless indicated otherwise in the credit line; if the material is not included under the Creative Commons license, users will need to obtain permission from the license holder to reproduce the material. To view a copy of this license, visit http://creativecommons.org/licenses/by/4.0/ 